\title{
Residual-Load-Bearing Capacity of High-Performance Concrete-Filled Box Columns after Fire
}

\author{
How-Ji Chen, Yuan-Chi Yang, Chao-Wei Tang, ${ }^{1 *}$ and Ching-Fang Peng \\ Department of Civil Engineering, National Chung-Hsing University, \\ No. 250, Kuo Kuang Road, Taichung 402, Taiwan \\ ${ }^{1}$ Department of Civil Engineering and Geomatics, Cheng Shiu University, \\ No. 840, Chengcing Rd., Niaosong Dist., Kaohsiung 83347, Taiwan
}

(Received September 30, 2016; accepted December 22, 2016)

Keywords: fire, high-performance concrete, steel box columns, residual-load-bearing capacity

In recent years, concrete-filled box columns (CFBCs) have been commonly used in high-rise buildings. In particular, steel box columns filled with high-performance concrete (HPC) are more common than concrete-encased steel columns. However, a number of fire test results show that there are significant differences between HPC and normal concrete after being subjected to high temperatures. Therefore, the residual strength of HPC-filled box columns exposed to fire was determined in this study. Two groups of full-size specimens were fabricated. The specimen of the control group was loaded at room temperature to achieve its ultimate load. On the other hand, fire tests were carried out on three specimens of the experimental group to investigate their residualload-bearing capacity after exposure to elevated temperatures $\left(400,600\right.$, and $\left.800{ }^{\circ} \mathrm{C}\right)$. To monitor and measure the temperature of the CFBC specimens during the fire test, an appropriate number of thermocouples were buried inside and outside the column. The thermocouples can effectively measure the temperature of the CFBC specimens during the fire test. The test results show that the residual ultimate strength of CFBC specimens increased at 400 and $600{ }^{\circ} \mathrm{C}$ by 5.2 and $1.0 \%$ respectively, compared with room-temperature strength. However, with a further increase in temperature to $800^{\circ} \mathrm{C}$, the residual ultimate strength was $15.7 \%$ lower than that of the control group at room temperature.

\section{Introduction}

Columns are the most important structural members in a building, and mainly transmit the building's weight and loads to the foundations. However, serious fires may cause column failure or collapse, thus affecting the structural safety of buildings. Therefore, the fire resistance of columns is extremely important in the fire protection design of buildings.

Steel-reinforced concrete (SRC) columns have been used in high-rise building projects with great advantage throughout the world over the past few decades. ${ }^{(1-14)}$ In particular, concrete-filled box columns (CFBCs) have several structural and practical benefits compared with bare steel or reinforced concrete columns. ${ }^{(4,12,14)}$ On the other hand, high-performance concrete (HPC) has unique properties in several aspects, such as rheology in its fresh state and strength as well as durability in its hardened state. ${ }^{(15-18)}$ The reason is that the changes made in the composition of the mixture 
of HPC lead to significant improvements in the properties of the fresh and hardened states. For instance, the use of pozzolanic materials will yield a relatively dense microstructure of the matrix.(19) Nevertheless, it may also lead to the explosive spalling behavior of HPC at a high heating rate, thus resulting in the failure of concrete elements. ${ }^{(20-23)}$

The use of HPC-filled box columns has been quite common in engineering practice in Taiwan. However, a number of fire test results show that there are significant differences between HPC and normal concrete after being subjected to high temperatures. ${ }^{(24-28)}$ Therefore, when HPC-filled steel box columns are subjected to an axial compressive load at high temperatures, it is likely to lead to loss of strength and differential thermal expansion because of the nature of the different composition materials. This phenomenon may affect the fire resistance of concrete-filled steel box columns. In view of the above, the residual-load-bearing capacity of HPC-filled box columns after exposure to elevated temperatures of $400-800{ }^{\circ} \mathrm{C}$ was determined in this study.

\section{Experimental Procedure}

\subsection{Experimental program}

In this study, four CFBC specimens consisting of square hollow structural sections filled with HPC were used. The design and planning of the CFBC specimens are given in Table 1. As can be seen in Table 1, two groups of full-size specimens were cast. The specimen (B0) of the control group was loaded at room temperature to achieve its ultimate load. On the other hand, fire tests were carried out on three specimens (B1, B2, and B3) of the experimental group to investigate their residual-load-bearing capacities after exposure to elevated temperatures $\left(400,600\right.$, and $\left.800{ }^{\circ} \mathrm{C}\right)$.

Before the fire test, external fire-proofing, which had a fire resistance rating of at least one hour, was provided for the steel of the experimental group. During the entire fire test, the column specimens were subjected to a constant compressive load. The fixed axial load was unloaded after the columns had cooled to room temperature. Then the axial compression load was gradually increased from zero until the specimens failed to support the load. The peak load obtained in the postfire test was defined as the residual ultimate strength of the columns. In addition to postfire test of CFBCs, the residual compressive strength test of HPC cylinders after exposure to elevated temperatures was also carried out.

Table 1

Design of CFBC specimens and summary of test information.

\begin{tabular}{lccccccc}
\hline Group type & Specimen No. & $B \times D \times t\left(\mathrm{~mm}^{3}\right)$ & $L(\mathrm{~mm})$ & $\eta_{f, t}$ & $F_{y s}(\mathrm{MPa})$ & $E_{s}(\mathrm{GPa})$ & $f_{c}^{\prime}(\mathrm{MPa})$ \\
\hline Control group & $\mathrm{B} 0$ & $400 \times 400 \times 12$ & 3000 & - & 414 & 205.9 & 51 \\
\hline \multirow{3}{*}{ Experimental group } & $\mathrm{B} 1$ & $400 \times 400 \times 12$ & 3000 & 0.28 & 414 & 205.9 & 51 \\
\cline { 2 - 8 } & $\mathrm{B} 2$ & $400 \times 400 \times 12$ & 3000 & 0.28 & 414 & 205.9 & 51 \\
\cline { 2 - 8 } & $\mathrm{B} 3$ & $400 \times 400 \times 12$ & 3000 & 0.28 & 414 & 205.9 & 51 \\
\hline
\end{tabular}

Notes: $B=$ breadth of the steel section; $D=$ depth of the steel section; $t=$ thickness of the steel section; $L=$ length of the column; $\eta_{f, t}=$ load level for fire design; $F_{y s}=$ yield strength of the steel; $E_{s}=$ steel modulus of elasticity; $f_{c}^{\prime}=$ compressive strength of concrete. 


\subsection{Casting of specimens}

The column specimens had square cross sections $\left(400 \times 400 \mathrm{~mm}^{2}\right)$ and were filled with HPC. All the columns were $3000 \mathrm{~mm}$ long. All the steel sections of the column specimens were made of steel plates of $22 \mathrm{~mm}$ thickness, as shown in Fig. 1. The plates were joined with a continuous fullpenetration weld. In addition, shear studs were provided for all the CFBC specimens to develop composite action between the steel plates and concrete. Moreover, 30-mm-thick end plates were welded to the top and bottom of the columns.

Materials used in the core concrete included cement, slag, fine aggregates, and coarse aggregates. The cement used here was Type I Portland cement with a specific gravity of 3.15 and a fineness of $3400 \mathrm{~cm}^{2} / \mathrm{g}$. The fine aggregate was natural river sand. The coarse aggregate was crushed stone with a maximum particle size of $19 \mathrm{~mm}$. The mix proportions for the HPC are shown in Table 2. The slump flow test, V-funnel test, and U-type test for the passing ability were adopted to assess the workability of the HPC. The aforementioned test results met regulatory requirements for self-compacting concrete. The measured average compressive strength $\left(f_{c}^{\prime}\right)$ of the cylinders on the testing day over all specimens was $51 \mathrm{MPa}$.

\subsection{Instrumentation and test procedures}

To monitor and measure the temperature of the CFBC specimens during the fire test, an appropriate number of thermocouples were buried inside and outside the column. The temperature from the CFBC surface to the inner central core was measured with type $\mathrm{K}$ thermocouples. Figure 2 shows that the thermocouples were placed at different depths in four sections of the column. As can be seen from Fig. 2, eleven thermocouples were placed in each section: six (S1-S6) were welded to the steel plate surface and the five others (C1-C5) were embedded in the concrete core

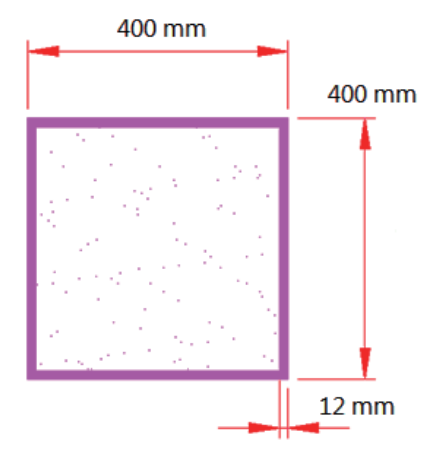

Fig. 1. (Color online) Cross section of CFBC specimens.

Table 2

Mix proportions of HPC.

\begin{tabular}{ccccccc}
\hline $\begin{array}{c}\text { Cement } \\
\left(\mathrm{kg} / \mathrm{m}^{3}\right)\end{array}$ & $\begin{array}{c}\text { Slag } \\
\left(\mathrm{kg} / \mathrm{m}^{3}\right)\end{array}$ & $\begin{array}{c}\text { Fly ash } \\
\left(\mathrm{kg} / \mathrm{m}^{3}\right)\end{array}$ & $\begin{array}{c}\text { Water } \\
\left(\mathrm{kg} / \mathrm{m}^{3}\right)\end{array}$ & $\begin{array}{c}\text { FA } \\
\left(\mathrm{kg} / \mathrm{m}^{3}\right)\end{array}$ & $\begin{array}{c}\mathrm{CA} \\
\left(\mathrm{kg} / \mathrm{m}^{3}\right)\end{array}$ & $\begin{array}{c}\text { SP } \\
\left(\mathrm{kg} / \mathrm{m}^{3}\right)\end{array}$ \\
\hline 356 & 76 & 76 & 178 & 889 & 780 & 8.14 \\
\hline
\end{tabular}

Notes: $\mathrm{FA}=$ fine aggregate, $\mathrm{CA}=$ coarse aggregate, $\mathrm{SP}=$ superplasticizer (HICON MTP A40). 


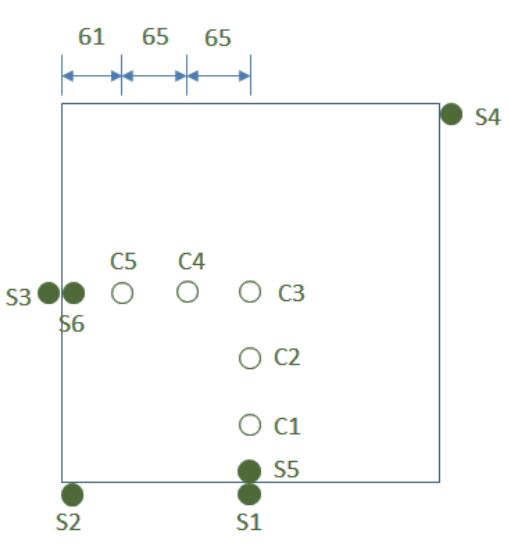

-Thermocouples S1-S6 for steel plate $\mathrm{O}=$ Thermocouples $\mathrm{C} 1-\mathrm{C} 5$ for concrete

Section A-A to Section D-D Unit: $\mathrm{mm}$

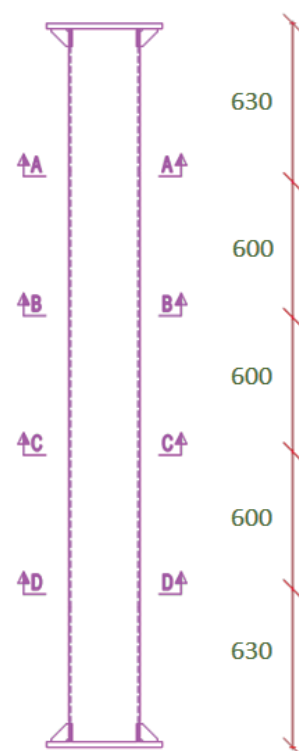

Fig. 2. (Color online) Scheme and layout of thermocouples for CFBC.

at various depths. A sufficient number of linear variable displacement transducers (LVDTs) were used to measure the axial displacements of the CFBC specimens. They were placed on the top and bottom of the test columns.

Prior to the fire test, the column specimen was installed in the furnace, and then a constant compression load was applied to the column specimen. The applied load corresponded to $28 \%$ of the nominal compressive strength of the specimen, which is the design value of the buckling resistance of the column at room temperature. The nominal compressive strength $P_{n}$ is defined in the Taiwan Design Code for SRC Structures as ${ }^{(29)}$

$$
\begin{gathered}
P_{n}=\varphi_{c s} P_{n s}+\varphi_{c r c} P_{n r c}, \\
P_{n s}=\left(0.211 \lambda_{c}^{3}-0.57 \lambda_{c}^{2}-0.06 \lambda_{c}+1\right) F_{y s} A_{s}, \\
P_{n r c}=\varphi_{e}\left(0.85 f_{c}^{\prime} A_{c}+A_{r} F_{y r}\right), \\
\lambda_{c}=\frac{K L}{\pi r_{e f f}} \sqrt{\frac{F_{y s}}{E_{s}}}, \\
r_{e f f}=r_{s}+\alpha \times \sqrt{\frac{I_{g}}{A_{g}}}, \\
r_{s}=\sqrt{\frac{I_{s}}{A_{s}}},
\end{gathered}
$$

where $P_{n s}$ is the nominal steel compressive strength and $P_{n r c}$ the nominal compressive strength of the reinforced concrete of the SRC column; $\varphi_{e}, \varphi_{c s}$, and $\varphi_{c r c}$ are resistance factors for compression; 
$A_{s}$ is the area of the steel cross section; $A_{c}$ is the area of concrete; $A_{r}$ is the area of longitudinal mild reinforcement; $A_{g}$ is the total area of the member; $F_{y s}$ is the yield strength of steel; $F_{y r}$ is the yield strength of the longitudinal mild reinforcement; $E_{s}$ is the steel modulus of elasticity; $f_{c}^{\prime}$ is the concrete strength; $\lambda_{c}$ is the slenderness parameter; $K$ is the effective length factor; $L$ is the lateral unbraced length of the member; $r_{s}$ is the governing radius of gyration; $\alpha$ is the correction factor for the effective radius of gyration; $I_{s}$ is the moment of inertia of steel; and $I_{g}$ is the moment of inertia of the total member section.

The ISO 834 standard fire curve was used for the testing of the column specimens in a natural gas-fired large-scale laboratory furnace until the average temperature of the thermocouples welded to the steel plate surface reached the target values. The temperature inside the furnace was controlled by adjusting 18 gas burners, and 14 thermocouples were used to monitor the furnace temperature at different locations. After the heating process, the specimens were allowed to cool slowly to room temperature in the furnace and then loaded with compressive force to failure.

In this study, the current failure criterion specified in ASTM E119 was adopted. ${ }^{(30)}$ Accordingly, the thermal failure of a CFBC specimen is said to occur when the average temperature of the measured points in steel plates exceeds the critical temperature, which is $593{ }^{\circ} \mathrm{C}$ for steel, or the steel temperature at any one of the measured points exceeds $649{ }^{\circ} \mathrm{C}$. Moreover, for the columns under consideration, the strength failure criteria correspond to a maximum contraction of $30.6 \mathrm{~mm}$ and a rate of contraction of $9.18 \mathrm{~mm} / \mathrm{min}$.

\section{Experimental Results and Discussion}

\subsection{Fire test results}

Fire tests were carried out on the specimens of the experimental group. Prior to the fire test, the predetermined axial compression load was applied to the column specimen. According to Eq. (1), the applied axial compression load was $2806.7 \mathrm{kN}$. The configured thermocouples can effectively measure the temperature of the $\mathrm{CFBC}$ specimens during the fire test. Once the furnace temperature reached the aforementioned termination conditions, the furnace was switched off and allowed to cool in the furnace with the door closed. In other words, the specimens cooled slowly. During the cooling phase, the applied axial load remained constant. The fire test results are shown in Table 3.

Table 3

Fire test results.

\begin{tabular}{lrrr}
\hline \multirow{2}{*}{ Item } & \multicolumn{3}{c}{ Specimen No. } \\
\cline { 2 - 4 } & $\mathrm{B} 1$ & $\mathrm{~B} 2$ & \multicolumn{1}{c}{$\mathrm{B} 3$} \\
\hline Termination temperature $\left({ }^{\circ} \mathrm{C}\right)$ & 400 & 600 & 800 \\
Duration of fire test $(\mathrm{min})$ & 22 & 78 & 105 \\
Average furnace temperature upon termination $\left({ }^{\circ} \mathrm{C}\right)$ & 795 & 985 & 1027 \\
Average outer surface temperature of steel plate upon termination $\left({ }^{\circ} \mathrm{C}\right)$ & 432 & 622 & 863 \\
Average inner surface temperature of steel plate upon termination $\left({ }^{\circ} \mathrm{C}\right)$ & 374 & 597 & 741 \\
Average temperature of steel plate upon termination $\left({ }^{\circ} \mathrm{C}\right)$ & 403 & 609 & 802 \\
Average temperature of concrete upon termination $\left({ }^{\circ} \mathrm{C}\right)$ & 89 & 274 & 462 \\
Axial deformation upon termination $(\mathrm{mm}){ }^{*}$ & 7.9 & 11.5 & -1.0 \\
Axial deformation after cooling $(\mathrm{mm})$ & -0.1 & -3.4 & -21.0 \\
\hline${ }^{*}$ Note: Positive values indicate expansion and negative values indicate contraction & &
\end{tabular}

"Note: Positive values indicate expansion and negative values indicate contraction. 
As shown in Table 3, the fire duration for the three specimens of the experimental group increased with increasing target temperature. The measured values of the average temperature of the steel plate upon shutdown of the furnace were 403,609 , and $802{ }^{\circ} \mathrm{C}$ for the B1, B2, and B3 specimens, respectively. These values were in close agreement with the target temperatures. In addition, the measured values of the average temperature of the concrete upon termination were 89,274 , and $462{ }^{\circ} \mathrm{C}$ for the $\mathrm{B} 1, \mathrm{~B} 2$, and $\mathrm{B} 3$ specimens, respectively. The average temperature difference between the concrete and the steel ranged from 310 to $350{ }^{\circ} \mathrm{C}$.

On the other hand, after turning off the furnace power switch, the axial deformations were 7.9, 11.5 , and $-1.0 \mathrm{~mm}$ for the B1, B2, and B3 specimens, respectively. Positive values indicate an expansion, whereas negative values indicate a contraction. These experimental results indicated that when the average temperature of the steel reached the target value, the B1 and B2 specimens were still in the expansion phase, which was mainly due to thermal expansion caused by the steel, whereas the B3 specimen exhibited a slight contraction because of a substantial decline in the steel modulus of elasticity. After cooling to room temperature, the specimens exhibited contraction owing to the action of the vertical fixed load. The axial deformations were $-0.1,-3.4$, and -21.0 $\mathrm{mm}$ for the B1, B2, and B3 specimens, respectively. This indicated that the B1 specimen should not suffer the adverse effects of fire exposure during the fire test because its axial deformation returned to its original shape. However, the B3 specimen suffered severe adverse effects during the fire test because its axial deformation increased significantly, as shown in Fig. 3. The reason is that when the average temperature of the steel reached $800{ }^{\circ} \mathrm{C}$, its strength and stiffness dropped significantly.

\subsection{Postfire test results}

Figure 4 shows the load versus axial deformation curve registered during the postfire test. Basically, the column specimens had undergone a contraction phase before being compressed to failure. Evidently, the B0 specimen of the control group had a high ultimate strength (11272.9 kN) because it did not suffer heat exposure. The measured ultimate strength for the $\mathrm{B} 0$ specimen was about $13 \%$ higher than the nominal ultimate strength $(10023.4 \mathrm{kN})$ calculated according to Eq. (1). From this, it can be concluded that the nominal ultimate strength adopted in the design on the basis

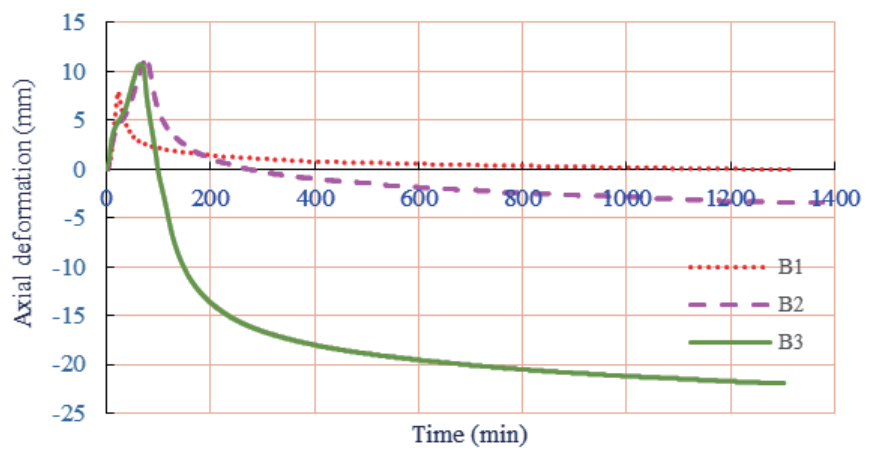

Fig. 3. (Color online) Axial deformation versus time curves for CFBC specimens.

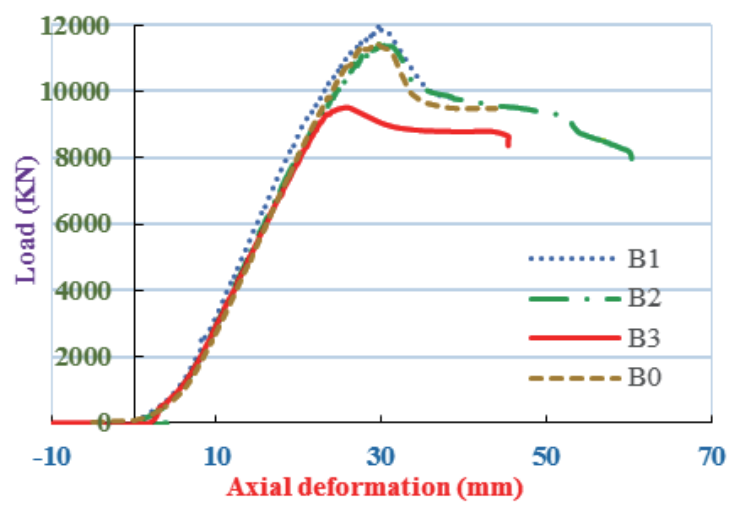

Fig. 4. (Color online) Load versus axial deformation curves for CFBC specimens. 
of the Taiwan Design Code for SRC Structures is more conservative than the measured ultimate strength obtained from this study.

Even if the average temperature of the steel plate in the $\mathrm{B} 1$ specimen reached $400{ }^{\circ} \mathrm{C}$, the average temperature of the inner concrete was only about $90{ }^{\circ} \mathrm{C}$ (Table 3 ). In other words, after the B1 specimen cooled, its strength should not be seriously degraded. In fact, as long as the concrete's temperature is below $200{ }^{\circ} \mathrm{C}$ during fire exposure, the compressive strength will increase after cooling. ${ }^{(19,31,32)}$ This increase in strength is considered to be mainly due to the rapid drying of concrete at high temperatures. ${ }^{(33)}$ As a result, the residual ultimate strength of the B1 specimen was $11860 \mathrm{kN}$, which is higher than the measured ultimate strength of the B0 specimen. Moreover, although the average temperature of the steel plate in the $\mathrm{B} 2$ specimen reached $600{ }^{\circ} \mathrm{C}$, the average temperature of concrete was about $275^{\circ} \mathrm{C}$ (Table 3). However, Fig. 5 shows that the duration in which the concrete in the $\mathrm{B} 2$ specimen was subjected to a temperature above $200{ }^{\circ} \mathrm{C}$ was only about $15 \mathrm{~min}$. As previously stated, the concrete compressive strength will increase after cooling. The measured residual ultimate strength of the B2 specimen was $11386.6 \mathrm{kN}$, which was about $4 \%$ lower than that of the B1 specimen. Even the residual ultimate strength of the B2 specimen was still slightly higher than the measured ultimate strength of the $\mathrm{B} 0$ specimen.

As for the B3 specimen, the average temperature of the steel plate reached $800{ }^{\circ} \mathrm{C}$; thus, its strength after cooling can be impaired to some extent. In addition, the average temperature of concrete in the $\mathrm{B} 3$ specimen was about $462{ }^{\circ} \mathrm{C}$ (Table 3). Figure 6 shows that the duration in which the concrete in the $\mathrm{B} 3$ specimen was subjected to a high temperature above $400{ }^{\circ} \mathrm{C}$ was $20 \mathrm{~min}$. However, the chemically bound water in the calcium silicate hydrates (CSHs) was released from the cement paste, which may lead to the failure of concrete at temperatures over $450{ }^{\circ} \mathrm{C}$, thus resulting in the loss of strength. ${ }^{(30-33)}$ Therefore, the measured residual ultimate strength of the B3 specimen was $9498.2 \mathrm{kN}$, which was sharply reduced by $15.7 \%$ compared with the room-temperature strength.

On the other hand, Fig. 7 shows the specimen's appearance after the postfire test. The experimental results indicate that similar failure modes were observed for the B1 and B2 specimens. The failure mode was the local buckling of the plate elements near the intermediate height of the

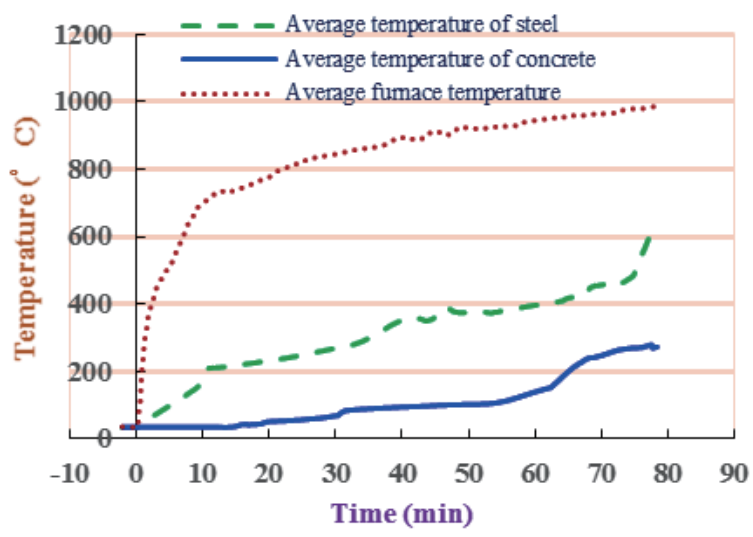

Fig. 5. (Color online) Temperature versus time curves for B2 specimen.

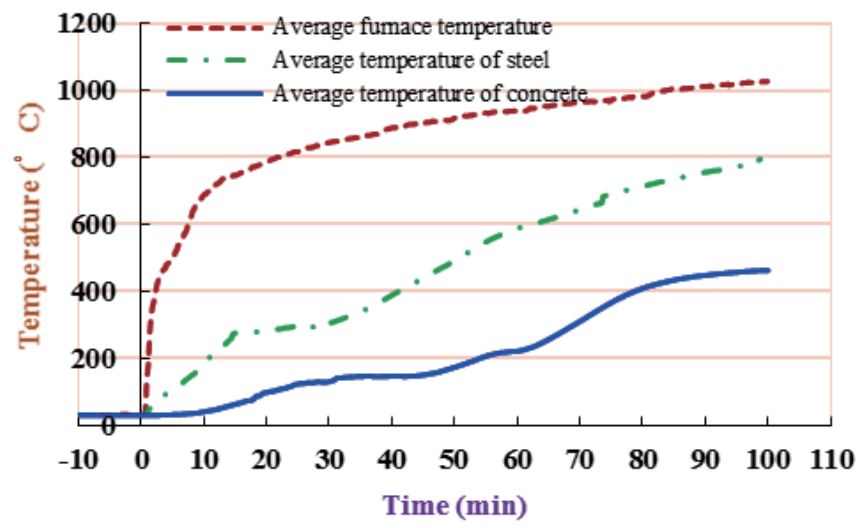

Fig. 6. (Color online) Temperature versus time curves for B3 specimen. 


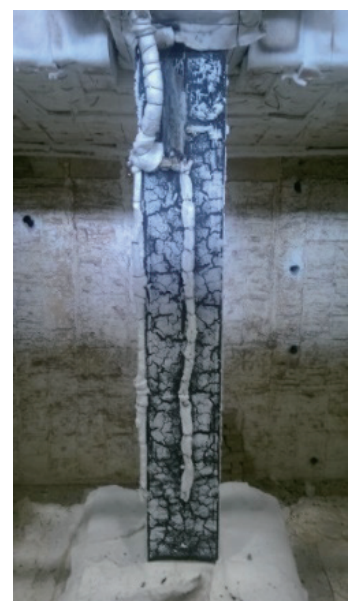

(a)

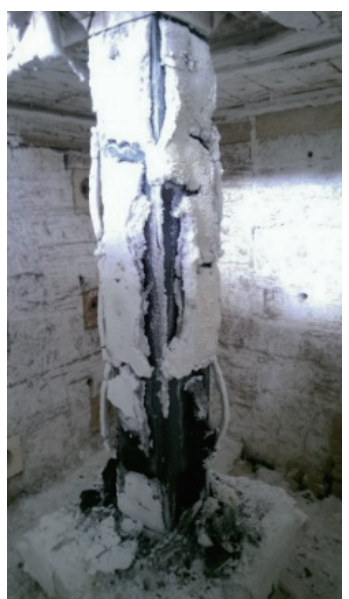

(b)

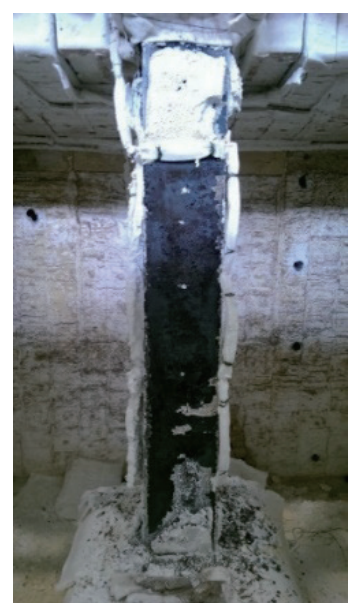

(c)

Fig. 7. (Color online) General view of specimens after test: (a) B1, (b) B2, and (c) B3 specimens.

specimen. In addition, some cracks propagated straight along the welded interfacial boundary. The failure mode for the B3 specimen was also the local buckling of the plate elements, but without weld bead cracking.

\subsection{Residual HPC compressive strength test results}

On the testing day for CFBC specimens, the 111-d cylindrical concrete specimens were placed in a computer-controlled electric furnace to perform a high-temperature test. The specimen was heated without preload at a prescribed rate until the temperature inside the furnace reached the target temperatures. When the targeted peak temperature was reached, the furnace temperature was maintained for half an hour to achieve a thermal steady state. The furnace was then switched off, and the cylindrical specimens were allowed to cool in the furnace with the door opened. After the cylindrical specimens cooled to room temperature, the residual compressive strength test was carried out.

The effect of temperature on the residual compressive strength of HPC at the age of $111 \mathrm{~d}$ is shown in Fig. 8. The residual compressive strength increased by $2.9 \%$ at $200{ }^{\circ} \mathrm{C}$ compared with the room-temperature strength. With a further increase in temperature to $400{ }^{\circ} \mathrm{C}$, the specimen reached a peak strength of $13.9 \%$ above the room-temperature strength. This result is different from the general description found in the literature. This is because the temperature inside the test specimen was still lower than $400{ }^{\circ} \mathrm{C}$ although the furnace temperature was maintained for half an hour. That is, the average temperature of the test specimen had not yet reached $400{ }^{\circ} \mathrm{C}$, so the residual compressive strength increased. However, at $600{ }^{\circ} \mathrm{C}$, the average temperature inside the concrete specimen should exceed $400{ }^{\circ} \mathrm{C}$, the compressive strength should decay, and its destruction would be caused by brittleness. As a result, the residual compressive strength dropped by $11.6 \%$ compared with the room-temperature strength. This may explain the strength decline of the B3 specimen. When the temperature was increased to $800{ }^{\circ} \mathrm{C}$, the residual compressive strength was $66.5 \%$ lower than that of the control at room temperature. In other words, the strength loss was very significant. 


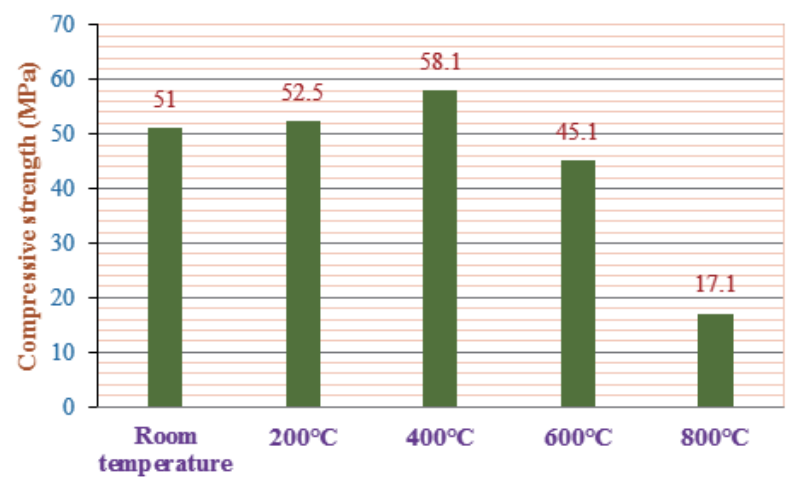

Fig. 8. (Color online) Effect of temperature on the residual compressive strength of HPC.

\section{Conclusions}

In this study, the residual-load-bearing capacity of full-size HPC-filled steel box columns after exposure to elevated temperatures was determined. On the basis of the above experimental results and discussion, the following conclusions were drawn.

(1) The measured ultimate strength of the B0 specimen was about $13 \%$ higher than the nominal ultimate strength calculated according to Eq. (1). It indicates that the nominal ultimate strength adopted in the design in accordance with the Taiwan Design Code for SRC Structures is more conservative than the measured ultimate strength.

(2) After cooling to room temperature, the axial deformations were $-0.1,-3.4$, and $-21.0 \mathrm{~mm}$ for the B1, B2, and B3 specimens, respectively. This indicated that the B1 specimen should not suffer adverse effects of fire exposure during the fire test because its axial deformation returned to its original shape. On the other hand, the B3 specimen severely suffered adverse effects during the fire test because its axial deformation increased significantly.

(3) The residual ultimate strengths of the B1 and B2 specimens were higher than the measured ultimate strength of the B0 specimen, mainly due to the rapid drying of the concrete.

(4) The measured residual ultimate strength of the B3 specimen was $9498.2 \mathrm{kN}$, which was sharply reduced by $15.7 \%$ compared with the room-temperature strength.

\section{Acknowledgements}

This work was supported by the Architecture and Building Research Institute (ABRI), Ministry of the Interior, Taiwan. The authors express their gratitude and sincere appreciation to ABRI for financing this research work.

\section{References}

1 T. T. Lie and V. K. R. Kodur: J. Struct. Eng. 122 (1996) 30.

2 V. K. R. Kodur, T. C. Wang, and F. P. Cheng: Cem. Concr. Compos. 26 (2004) 141.

3 D. K. Kim, S. M. Choi, J. H. Kim, K. S. Chung, and S. H. Park: Steel Struct. 5 (2005) 305.

4 L. H. Han, G. H. Yao, and X. L. Zhao: J. Constr. Steel. Res. 61 (2005) 1241.

5 V. K. R. Kodur: Steel Struct. 7 (2007) 173. 
6 J. Ding and Y. C. Wang: J. Constr. Steel. Res. 64 (2008) 1086.

7 S. Hong and A. H. Varma: J. Constr. Steel. Res. 65 (2009) 54.

8 A. Espinos, A. Hospitaler, and M. L. Romero: Acta Polytech. 49 (2009) 39.

9 H. Lu, X. L. Zhao, and L. H. Han: J. Constr. Steel. Res. 65 (2009) 1995.

10 T. Y. Song, L. H. Han, and H. X. Yu: J. Constr. Steel. Res. 66 (2010) 369.

11 B. Persson: Cem. Concr. Res. 31 (2001) 193.

12 Z. Tao, M. Ghannama, T. Y. Song, and L. H. Han: J. Constr. Steel. Res. 118 (2016) 120.

13 N. Mago and S. J. Hicks: J. Constr. Steel. Res. 119 (2016) 123.

14 T. Ekmekyapar: J. Constr. Steel. Res. 117 (2016) 175.

15 C. Frazão, A. Camões, J. Barros, and D. Gonçalves: Constr. Build. Mater. 80 (2015) 155.

16 M. F. Granata: Constr. Build. Mater. 96 (2015) 581.

17 S. Grünewald and J. C. Walraven: Cem. Concr. Res. 31 (2001) 1793.

18 M. I. Kaffetzakis and C. G. Papanicolaou: Constr. Build. Mater. 113 (2016) 641.

19 P. K. Metha and P. J. M. Monteiro: Concrete: Microstructure, Properties and Materials, 3rd ed. (McGraw-Hill, New York, 2006).

20 A. Bilodeau, V. K. R. Kodur, and G. C. Hoff: Cem. Concr. Compos. 26 (2004) 163.

21 C. Castillo and A. J. Durrani: ACI Mater. J. 87 (1990) 47.

22 G. Sanjayan and L. J. Stocks: ACI Mater. J. 90 (1993) 170.

23 L. T. Phan, J. R. Lawson, and F. L. Davis: Mater. Struct. 34 (2001) 831.

24 A. Noumowé, H. Carré, A. Daoud, and H. Toutanji: J. Mater. Civ. Eng. 18 (2006) 754.

25 H. Fares, H. Toutanji, K. Pierce, and A. Noumowé: J. Mater. Civ. Eng. 27 (2015). doi: 10.1061/(ASCE)MT.1943-5533.0001285

26 X. Wu, Z. Wu, J. Zheng, T. Ueda, and S. Yi: Mag. Concrete. Res. 65 (2013) 780.

27 L. T. Phan and N. J. Carino: J. Mater. Civ. Eng. 10 (1998) 58.

28 L. T. Phan and N. J. Carino: ACI Mater. J. 99 (2002) 54.

29 Design Code and Commentary for Steel Reinforced Concrete Structures (Taiwan Construction and Planning Agency, Taipei, 2004) (in Chinese).

30 ASTM Test Method E119-01: Standard Methods of Fire Test of Building Construction and Materials (American Society for Testing and Materials, West Conshohocken, PA, 2001).

31 S. Mindess, J. F. Young, and D. Darwin: Concrete (Prentice-Hall, Inc., New Jersey, 2002).

32 I. Janotka and L. Bágel: ACI Mater. J. 100 (2003) 87.

33 R. Siddique and D. Kaur: J. Adv. Res. 3 (2012) 45. 